\title{
Sexually transmitted diseases: A significant complication of childhood sexual abuse
}

\author{
DEBORAH LINDSAY, MD, FRCPC, JOANNE EMBREE, MD, FRCPC
}

\begin{abstract}
D Lindsay, J Embree. Sexually transmitted diseases: A significant complication of childhood sexual abuse. Can J Infect Dis 1992;3(3):122-128. The acquisition of one or more sexually transmitted diseases (STD) is a significant complication of sexual assault of children. The risk of infection by pathogens varies from less than 1 to $50 \%$ depending on the nature of the assault, the organism studied and the background prevalence of STD in the general community. The correct diagnosis of STD in children depends upon optimal collection and appropriate laboratory testing of clinical specimens. Diagnosing STD will allow for treatment and follow-up to ensure cure of these infections as well as to monitor for re-infection. It will also help confirm that sexual activity involving the child has occurred. This can be extremely important, particularly when there are minimal other physical findings of abuse or if the child has limited verbal skills and thus cannot provide a complete disclosure. All physicians who care for children should be knowledgeable about the methods of STD diagnosis and the currently recommended treatment regimens.
\end{abstract}

Key Words: Sexual abuse, Sexually transmitted disease, STD diagnosis, STD prevalence, STD treatment

\section{Les maladies transmises sexuellement: Une complication importante chez l'enfant victime de sévices sexuels}

RESUME: L'acquisition d'une ou de plusieurs maladies transmises sexuellement (MTS) est une complication importante des sévices sexuels infligés aux enfants. Le risque d'infection par les agents pathogènes incriminés varie de moins de $1 \%$ à $50 \%$ selon la nature des mauvais traitements, l'organisme étudié et la prévalence de MTS dans la collectivité en général. Le diagnostic correct de MTS posé chez l'enfant dépend d'un interrogatoire minutieux et les prélèvements doivent faire l'objet d'analyses de laboratoire appropriées. Tout en assurant la guérison par un traitement et un suivi adaptés, ce diagnostic permet de rester attentif à toute réinfection éventuelle. Il contribue aussi à confirmer toute activité sexuelle engageant l'enfant. Cette constatation peut s'avérer extrêmement importante, surtout quand les autres preuves physiques d'abus font défaut ou quand la capacité d'expression de l'enfant est limitée, excluant une divulgation complète. Tous les médecins qui traitent les enfants devraient connaître les méthodes de diagnostic des MTS et les traitements actuellement recommandés.

The Child Protection Centre, Children's Hospital; and the Departments of Pediatrics, Child Health and Medical Microbiology. University of Manitoba, Winnipeg, Manitoba

Correspondence and reprints: Dr JE Embree, Room 530 Basic Medical Science Building, 730 William Avenue, Winnipeg.

Manitoba R3E OW3. Telephone (204) 788-6630

Received for publication February 14, 1991. Accepted May 21, 1991 
S EXUAL ABUSE OF CHILDREN IS A DISTURBING SUBJECT TO most of us. The increasing awareness of this problem over the past two decades has led to numerous studies by medical, legal and related researchers concerning the prevalence of abuse, characteristics of offenders, victims and families, the physical findings in abused children, credibility of allegations, the legal issues pertaining to the child and court, and acquisition of sexually transmitted diseases (STD) by children through sexual abuse (1-8). In this article, the body of this knowledge will be reviewed as it relates to the acquisition, diagnosis and management of these infections in this population.

\section{BACKGROUND}

Sexual abuse refers to the sexual exploitation of a child by another person, and encompasses both direct physical acts, such as fondling and digital or penile penetration of the vagina, as well as nonphysical acts such as exhibitionism or procuring. The Badgely Commission Report released in 1984 (5) suggested that as many as one in two females and one in three males have been victims of a sexual offence at some time in their lives. Most offences occur prior to the age of 21 years; acts of exposure are the largest category of offences against youth. By the age of 16 years, however, as many as 5 to $9 \%$ of males and 15 to $20 \%$ of females have experienced some form of unwanted sexual touching, with intercourse occurring in 1 to $3 \%$. Based upon reporting trends across North America over the past 10 to 15 years, the numbers of reported cases of child abuse, and the percentage which are sexual in nature, are increasing $(1,7,9)$. At the Child Protection Centre in Winnipeg, Manitoba, the number of referrals for child abuse have increased from 372 in 1982 to 1157 in 1990, with an increase from 30.6 to $58.8 \%$ of cases being sexual in nature. This likely reflects an increase in both public and professional awareness resulting in a corresponding increase in recognition and reporting, since the actual number of cases in relation to population growth has remained at a relatively constant level (5).

Sexual abuse in children is a widespread problem; however, certain trends and generalities have been identified. Many victims have previously been living with nonbiological parents, in homes where alcohol and/or drugs are abused, in families already known to child welfare agencies or in families with a history of physical abuse $(2,3)$. Family units in which adolescent males spend prolonged unsupervised time with young children are considered higher risk. A large percentage of victims are children of parents who were themselves the victims of childhood sexual abuse. The majority of children seen currently ( 80 to $90 \%$ ) are female victims of male offenders; however, many retrospective studies have shown that a much larger number of males than expected describe sexual abuse in childhood $(2,3,5)$. Usually offenders are known to the child either as a family member, friend or acquaintance, or guardian; only a small percentage ( 1 to $17 \%$ ) are strangers $(2,4,5)$. Most allegations are substantiated; false allegations which are often initiated by an adult make up 6 to $11 \%$ of unsubstantiated cases $(5,10)$. Only approximately $40 \%$ of cases will result in charges being laid (5).

\section{EPIDEMIOLOGY}

The reported prevalences of the sexually transmitted pathogens found in abused children vary considerably (Table 1). This is partly due to differences in study population definition. Differences related to using an absolute age limit for prepubescence (hence including some early pubertal children) versus Tanner staging are important, since significant changes occur in the pathogenesis of many vaginal infections, in particular Chlamydia trachomatis and Neisseria gonorrhoeae, once puberty begins $(11,12)$. The identity of the abuser is significant, as family members who do not engage in sexual activity outside the family are less likely to pass on STD. For example, the number of children diagnosed with gonorrhea is lower if the offender was the father or stepfather as opposed to another relative or a family friend (7). In families where there is drug or alcohol abuse, the risk is increased as STD are more prevalent in this adult population (12). The type of abuse also plays a role. Sexual activities such as exhibitionism are unlikely to lead to the transmission of STD since there is little opportunity for passage of infected genital secretions to the child. The risk of infection is greater with actual sexual intercourse, but penetration need not take place for STD transmission to occur. The sexual abuser who masturbates and ejaculates, and then fondles the child, may transmit the organism in that fashion. Victims of repeated episodes of abuse have a greater risk of infection than those experiencing only a single episode (8). There may also be clustering of STD if more than one child is sexually abused by an infected individual (13-16). The prevalence of STD varies from community to community. In communities where there is a high endemic rate of gonorrhea, there is an equally high rate of gonorrheal isolation among sexually abused children (7). Finally, many studies have not considered the full spectrum of etiological agents due to difficulty in collecting multiple, good samples from a female child, since prior to maturation of the genital tissue, the introitus is quite sensitive to touch.

Determining that an infection is sexually transmitted, isolated because of prolonged perinatal carriage, or acquired in a nonsexual fashion, may be difficult but is important. For example, Gardnerella vaginalis is not exclusively sexually transmitted in young children (17); thus, its isolation may not be indicative of sexual abuse if no other findings of abuse are present. Lack of suitable control populations have interfered with interpretation of the large studies designed to examine this problem. Control groups have often comprised clinic 
TABLE 1

Reported prevalences of sexually transmitted diseases in abused children

\begin{tabular}{|c|c|c|c|c|c|}
\hline \multirow{2}{*}{$\begin{array}{l}\text { Study (year) (reference) } \\
\text { Neisseria gonorrhoeae }\end{array}$} & & & \multirow[t]{2}{*}{ Location } & \multicolumn{2}{|c|}{ Prevalence (\%) } \\
\hline & & & & & \\
\hline Tilelli & (1980) & (1) & Minnesota, USA & $3 / 113$ & $(2.6 \%)$ \\
\hline Khan & (1983) & (2) & Maryland, USA & $14 / 71$ & $(19.7 \%)$ \\
\hline Grant & (1984) & (3) & Manitoba, Canada & $12 / 157$ & $(7.6 \%)$ \\
\hline Rimsza & (1982) & (4) & Arizona, USA & $21 / 285$ & $(7.4 \%)$ \\
\hline White & (1983) & (7) & North Carolina, USA & $46 / 409$ & $(11.2 \%)$ \\
\hline DeJong & (1986) & (8) & Pennsylvania, USA & $25 / 532$ & $(4.6 \%)$ \\
\hline Ingram & (1984) & (19) & North Carolina, USA & $10 / 50$ & $(20 \%)$ \\
\hline Hammerschlag & (1984) & $(47)$ & New York, USA & $5 / 51$ & $(10 \%)$ \\
\hline Dattel & (1989) & $(48)$ & California, USA & $15 / 127$ & $(12 \%)$ \\
\hline Wald & $(1980)$ & $(29)$ & Maryland, USA & $28 / 189$ & $(14.8 \%)$ \\
\hline Ingram & $(1986)$ & $(20)$ & North Carolina, USA & $13 / 124$ & $(10.8 \%)$ \\
\hline \multicolumn{6}{|l|}{ Chlamydia trachomatis } \\
\hline DeJong & $(1986)$ & $(8)$ & Pennsylvania, USA & $1 / 438$ & $(0.2 \%)$ \\
\hline Ingram & (1984) & (19) & North Carolina, USA & $3 / 50$ & $(6 \%)$ \\
\hline Hammerschlag & (1984) & $(47)$ & New York, USA & $2 / 51$ & $(4 \%)$ \\
\hline Dattel & $(1989)$ & $(48)$ & California, USA & $18 / 127$ & $(14 \%)$ \\
\hline Ingram & $(1986)$ & $(20)$ & North Carolina, USA & $10 / 124$ & $(8 \%)$ \\
\hline Fuster & $(1987)$ & $(49)$ & California, USA & $8 / 47$ & $(17 \%)$ \\
\hline Porder & $(1989)$ & $(36)$ & New York, USA & $0 / 65$ & $(0 \%)$ \\
\hline \multicolumn{6}{|l|}{ Trichomonas vaginalis } \\
\hline White & (1983) & (7) & North Carolina, USA & $4 / 409$ & $(1 \%)$ \\
\hline DeJong & $(1986)$ & (8) & Pennsylvania, USA & $2 / 438$ & $(0.5 \%)$ \\
\hline Hammerschlag & $(1985)$ & $(44)$ & New York, USA & $1 / 31$ & $(3 \%)$ \\
\hline \multicolumn{6}{|l|}{ Ureaplasma urealyticum } \\
\hline Hammerschlag & (1987) & (18) & New York, USA & $21 / 47$ & $(45 \%)$ \\
\hline \multicolumn{6}{|l|}{ Mycoplasma hominis } \\
\hline Hammerschlag & $(1987)$ & (18) & New York, USA & $18 / 47$ & $(38 \%)$ \\
\hline \multicolumn{6}{|l|}{ Nonspecific vaginosis } \\
\hline Hammerschlag & $(1985)$ & $(44)$ & New York, USA & $8 / 31$ & $(26 \%)$ \\
\hline \multicolumn{6}{|l|}{ Treponema pallidum } \\
\hline White & (1983) & (7) & North Carolina, USA & $6 / 409$ & $(1.4 \%)$ \\
\hline DeJong & $(1986)$ & $(8)$ & Pennsylvania, USA & $1 / 532$ & $(0.1 \%)$ \\
\hline
\end{tabular}

patients felt not to have been sexually abused or previously abused patients, and so may not truly reflect the 'normal' population (18-20). Also, the numbers of children studied are often insufficient to show moderate differences in prevalence.

Duration of colonization of perinatally acquired STD is not known for the majority of pathogens. Perinatally acquired gonorrhea is not thought to persist past the neonatal period (15). Chlamydia was not detected in a sample of 131 children at one year of age who were born to culture positive mothers (21). However, untreated adult women may carry the organism for up to two years (12). Trichomonas vaginalis has only rarely been isolated after one month of age (22). While the prevalences of genital mycoplasmas are low in prepubertal age groups (range 4 to 22\%), the duration of perinatal colonization is unknown $(18,23)$. No genital mycoplasmas were isolated from children followed beyond one year of life in one study (24). The acquisition of anaerobic bacterial vaginosis at delivery by infants has not been studied.
Uncertainty concerning the frequency of duration of the latency period of human papillomavirus complicates the diagnosis of sexual abuse in the child who presents with condyloma acuminatum. Although an average latency period of three months has been quot ed, incubation periods of longer duration are likely (25) Since the lesions may persist for many years without treatment, perinatal transmission could be the mode of acquisition in the older child (older than two years) who is found to have genital warts during a physical ex amination. However, this should not preclude evalua tion for other evidence of sexual abuse $(25,26)$.

Another controversy centres on nonsexual transmission of STD, in particular gonorrhea, after the perinatal period. Although gonorrhea has been isolated in fomites and on porcelain toilet bowls, this mode of transmission has never been implicated in the transmission of $N$ gonorrhoeae. Most care givers assume that children acquire gonorrhea through sexual contact (27). This includes children who acquire gonorrhea from a sibling or playmate of the same age through 
TABLE 2

Sites for specimen collection to diagnose sexually transmitted diseases in prepubertal children

\section{Pharynx}

Neisseria gonorrhoeae culture

Rectum

Neisseria gonorrhoeae culture

Chlamydia trachomatis culture

Herpes simplex virus culture

Urethra (males)

Neisseria gonorrhoeae culture

Chlamydia trachomatis culture

Herpes simplex virus culture

Urine

Examine for Trichomonas vaginalis

Vagina

Neisseria gonorrhoeae culture

Chlamydia trachomatis culture

Aerobic bacterial culture

Microscopic examination of wet mount preparation/

exudate for:

Trichomonas vaginalis

Clue cells

Yeast

Amine odour

Herpes simplex virus culture

Genital ulcers

Aerobic bacterial culture

Herpes simplex virus culture

Hemophilus ducreyi culture

Examination of exudate for Treponema pallidum

Genital warts

Clinical evaluation

Serological samples

Syphilis

Human immunodeficiency virus

Hepatitis B

Frozen sample to be saved

sexual play acting; one of the children has been sexually abused, although not necessarily the index child (13-16). A potential nonsexual transmission scenario has been suggested by Shore and Winkelstein (28) who investigated Inuit children in which all family members shared the same bed and in which gonorrhea was found in a very high proportion of the children. Based only on the lack of a history of sexual abuse Shore and Winkelstein concluded that sexual transmission was not the mode of gonococcal acquisition. Four of the infected children had gonococcal conjunctivitis which implied hand-to-eye transmission. However, the crowded conditions in this study are unique to the population studied, and the conclusions drawn by the authors, even if correct, cannot be generalized.

\section{DIAGNOSIS AND MANAGEMENT}

The diagnosis of STD in abused children is complicated by difficulty in obtaining the necessary specimens from prepubertal children, and the lack of sensitivity and specificity of tests used to detect or isolate the different pathogens. Ideally, the approach to diagnosis of STD should involve testing for all potential pathogens if sexual abuse of a nature allowing transmission of
STD is suspected. The availability of laboratory facilities may limit this approach.

A careful genital examination, including STD testing, in a calm, relaxed child should cause little or no discomfort. Often, however, the abused child is afraid, anxious or uncooperative, resulting in an examination which is uncomfortable, particularly during specimen collection. Time spent in preparing the child for the examination will alleviate many of the anxieties and allow for an easier examination. At many sexual abuse clinics a child life therapist spends time with the patient prior to the actual examination. Simple things such as an explanation of equipment, allowing a child to examine a doll with medical equipment, and letting a child touch swabs (dry and wet) may alleviate some fears.

The actual examination should consist initially of maneuvres which are both familiar to a child and nonhurtful, such as listening to the chest. This enables the child to become familiar and comfortable with the examining procedures. The genital examination is best done with the child in the supine position, with the legs bent at the knee and abducted at the hip - the 'frog-leg position'. An alternate position is with the child on the parent's lap with the parent helping to abduct the legs. Slight traction of the vulva towards the examiner and slightly down will allow for the best visualization of the introitus. In the relaxed child, this position will enable the vaginal orifice to open. With care, a small moistened Calgi type I swab can then be inserted through the orifice. If the hymenal ring is not touched, there is usually little sensation associated with the swabs. A speculum examination is only rarely required and in this age group is best done under general anesthetic.

Sites which should be cultured for each STD are shown in Table 2. Because most prepubertal children are seen well after the episode(s) of abuse, a single sample taken for STD at the time of assessment will suffice. For children seen immediately after an acute episode, initial cultures may be negative and should be repeated in two to three weeks.

Neisseria gonorrhoeae: Asymptomatic infection with $N$ gonorrhoeae frequently occurs; thus, reliability of vaginal, rectal or pharyngeal exudates as an indication of likely infection is poor $(14,15,29,30)$.

Adequate specimens of exudate or swabs of mucosal surfaces should be obtained and plated immediately onto antibiotic-containing selective media (such as modified Thayer-Martin media) and incubated to maximize the chances of recovery of the organism. Several Neisseria species may be falsely identified as $N$ gonorrhoeae and may thus lead to false allegations of sexual abuse (31). Isolates should be identified using more than one identification procedure and should ideally be fowarded to a reference laboratory for confirmation.

Empiric treatment for chlamydia infection may be warranted while awaiting results of culture, since as 
many as one-third of cases of gonorrhea are complicated by concomitant infection with chlamydia (32).

Repeat cultures of infected sites for 'test of cure' are recommended for all patients with gonorrhea. Particular attention should be given to children with the organism isolated from the throat, as eradication of infection at this site is difficult. A throat swab for $N$ gonorrhoeae should be included in the initial investigation of genital or rectal gonorrhea. The 'test of cure' cultures for gonorrhea should be done four to five days following completion of the antibiotic treatment course. Chlamydia: Chlamydia may also be isolated from young girls with symptomatic vaginitis, but its role as a causative agent in this condition remains unclear (18,19,3234). Currently, a controversy exists regarding the sensitivity and specificity of rapid diagnostic testing methods for $C$ trachomatis when used in the abused child population. The successful use of enzyme assays or fluorescent antibody tests for rapid culture-independent diagnosis of chlamydia infections in adult patients led to testing of these products in children (35). There are significant problems when these tests are used for specimens obtained from the genitourinary tract or the rectum of children, due to false positive results when specimens contain other bacterial elements (36-40). Mathematical calculations based on the theoretical performance of existing tests on populations of low seroprevalence indicate that currently used tests have a positive predictive value of only $50 \%$ in situations of child abuse (41). Manufacturers of these products are examining laboratory manipulations such as blocking antibodies in the test system to obviate most, if not all, false positive reactions.

At present, the diagnosis of genital or rectal chlamydia infections in prepubertal children is dependent on isolation of the organism from the vagina, urethra or rectum. Dacron swabs may be toxic to chlamydia; therefore, Calgi swabs are used to collect cells from the lining of the vagina or urethra. Less invasive procedures such as early phase voided urine specimens or vaginal washes are under assessment. Samples should be placed in chlamydia transport media and transported on wet ice to the laboratory. Specific arrangements regarding appropriate handling of chlamydia culture specimens should be made with the laboratory if there will be a delay of greater than $4 \mathrm{~h}$ in specimen transport.

Vaginitis: Children who present with symptoms or signs of vaginitis such as vulvar or vaginal itching, urinary frequency or painful urination, vulvar or vaginal inflammation, or vaginal discharge, should be investigated for STD and non-STD pathogens $(42,43)$. Samples of vaginal secretions can be obtained using a swab from the vagina suspended in saline or an aspirate of vaginal secretions (possibly diluted with sterile saline). These samples should be studied under the microscope for the presence of trichomonads, candida and 'clue cells'.
Suspension of a drop of the sample mixed with 10\% potassium hydroxide will give off a distinctive offensive fishy amine odour if anaerobic organisms producing vaginitis are present (44). The chocolate agar of the modified Thayer-Martin split plate often used for detection of gonococci should be adequate to isolate an aerobic non-STD bacterial cause of vaginitis such as streptococci, staphylococci or enterobacteriaceae. Candida may also be recovered from this culture.

Cultures for $N$ gonorrhoeae and $C$ trachomatis should be obtained as described previously. Examination for pinworm infection may be warranted. Treatment of non-STD aerobic organisms or candida will depend upon culture results and the patient's underlying condition.

Genital ulcer disease: If present, genital ulcers should be tested for detection of herpes simplex virus. Treponema pallidum, Haemophilus ducreyi (if chancroid is present in the community) and aerobic non-STD pathogens. The initial differential diagnosis will depend upon the appearance of the ulcer and the presence of pain or other symptoms. Classically, the primary chancre of syphilis is painless, whereas genital ulcers with other etiologies are usually extremely painful.

The ulcer base should be cleaned and swabs taken for the diagnostic specimen. Material should be sent in viral transport media to a virology laboratory for herpes simplex virus isolation and typing if possible. If syphilis is suspected, a swab of the base should be tested immediately by fluorescent darkfield examination. The diagnosis of $H$ ducreyi involves the use of specialized media; the sample should be plated immediately on this media (45).

Genital warts: Diagnosis is by inspection of the genital area. The wart may be biopsied and DNA hybridization or polymerase chain reaction testing for STD strains performed if there is doubt concerning the type of wart. Treatment depends upon the location and size of the warts and may involve the use of topical agents such as podophyllin or liquid nitrogen, or may necessitate surgical removal $(25,26)$. Podophyllin is often not well tolerated. Recurrences are frequent despite therapy. Use of interferon alpha-2b is currently under investigation (25).

Inapparent infections - Latent syphilis, HIV, hepatitis B: These infections are diagnosed using serological tests. Testing is at the discretion of the physician and is based upon the risk of acquisition of the illness. The risk of syphilis is estimated to be less than $1 \%$ in areas of low prevalence of this disease in the adult population. and only a few cases of human immunodeficiency virus (HIV) or hepatitis B transmission have been described $(7,8,46)$. If testing is done, the rapid plasma reagin (RPR) or VDRL screening tests should be confirmed with an additional test (usually $T$ pallidum hemagglutination). An initially positive HIV antibody test should also be repeated to confirm the diagnosis. Both syphilis and HIV 


\section{TABLE 3}

\section{Treatment of sexually transmitted pathogens in children}

\section{Neisseria gonorrhoeae}

If the organism has been isolated and found to be sensitive to penicillins, amoxicillin or ampicillin $100 \mathrm{mg} / \mathrm{kg}$

(maximum $3.0 \mathrm{~g}$ ) per ora plus probenecid $25 \mathrm{mg} / \mathrm{kg}$

(maximum $1.0 \mathrm{~g}$ ) per ora (single dose)

If penicillinase-producing Neisseria gonorrhoeae present in

community or if unknown

- Cefixime 8 mg/kg (maximum 400 mg) per ora or

- Ceftriaxone 250 mg intramuscularly or

- Spectinomycin 40 mg/kg (maximum $2.0 \mathrm{~g}$ ) intramuscularly (not if pharyngeal infection present) or

- Erythromycin 40 mg/kg/day (maximum 2 g/day in divided doses) per ora for seven days

\section{Chlamydia trachomatis}

Erythromycin $40 \mathrm{mg} / \mathrm{kg} /$ day qid per ora (maximum $2 \mathrm{~g} /$ day) in divided doses for 14 days

or

Sulphamethoxazole $75 \mathrm{mg} / \mathrm{kg} /$ day bid per ora

(maximum $1.0 \mathrm{~g}$ bid) for 10 days

\section{Trichomonas vaginalis}

Metronidazole 15 mg/kg/day (maximum 500 mg bid) per ora for seven days

Nonspecific vaginosis

Metronidazole $15 \mathrm{mg} / \mathrm{kg} /$ day (maximum $500 \mathrm{mg}$ qid) per ora for seven days

\section{Haemophilus ducreyi}

Erythromycin $40 \mathrm{mg} / \mathrm{kg} /$ day (maximum $2 \mathrm{~g} /$ day) in divided doses per ora for seven days

or

Ceftriaxone $250 \mathrm{mg}$ intramuscularly single dose

or

Amoxicillin-clavulanic acid $40 \mathrm{mg} / \mathrm{kg} /$ day per ora for three days

\section{Herpes simplex virus}

Symptomatic: acyclovir $5 \mathrm{mg} / \mathrm{kg}$ every $8 \mathrm{~h}$ intravenously for five days

Acyclovir $600 \mathrm{mg} / \mathrm{m}^{2} /$ dose per ora four times per day for 10 days (investigational)

Early syphilis (less than one year)

Benzathine penicillin $\mathrm{G}$ 100,000 units/kg (maximum 2.4 million units) intramuscularly once at two sites

or

Penicillin-allergic patients for whom desensitization is not possible, erythromycin $40 \mathrm{mg} / \mathrm{kg} /$ day (maximum $2 \mathrm{~g} /$ day) in divided doses per ora for 14 days (not as efficacious as penicillin therapy)

\section{Latent syphilis (one year or longer)}

Benzathine penicillin $\mathrm{G} 100,000$ units/kg (maximum 2.4 million units) intramuscularly once weekly for three weeks plus probenecid $25 \mathrm{mg} / \mathrm{kg}$ per ora

or

Procaine penicillin 25,000 units/kg (maximum 600,000 units) intramuscularly once daily for 14 days

or

For penicillin-allergic patients for whom desensitization is not possible, erythromycin $40 \mathrm{mg} / \mathrm{kg} /$ day (maximum $2 \mathrm{~g} / \mathrm{day}$ )

in divided doses per ora for 28 days

Human papillomavirus

Podophyllin, liquid nitrogen, surgery

Interferon alpha-2b (investigational) have latent periods, and so, in high risk situations, the tests need to be repeated if the initial one is negative (six weeks for syphilis, six months for HIV). Treatment for syphilis is dependent upon disease stage and requires follow-up serological testing at three-month intervals until the VDRL or RPR tests become nonreactive. Management of children with HIV infection involves emotional support, prevention of opportunistic infection, and administration of antiviral agents to delay progression of the illness once immune suppression occurs. There is no specific treatment for hepatitis B infection.

A summary of antibiotic treatment regimens for children is found in Table 3. In addition to the suggested therapies, tetracycline or doxycycline are alternative antibiotic treatments for syphilis, gonorrhea and chlamydial infections in children nine years or older. Empiric treatment for STD in instances of acute assault is at the discretion of the physician. If done, treatment should be directed against syphilis, gonorrhea and chlamydia. 'Test of cure' specimens should be obtained following this therapy.

\section{SUMMARY}

The importance of correct diagnosis of the presence of STD in abused children cannot be overemphasized, nor can the necessity of testing for additional STD pathogens following the identification of one STD be ignored. Of prime importance is that identification of STD allows for appropriate treatment and follow-up. As well the presence of one or more STD helps confirm that sexual activity has occurred. This may be extremely important, particularly in the child with minimal physical findings suggestive of abuse, or in the child with limited verbal skills who is unable to give complete disclosure. As knowledge of STD epidemiology, diagnosis and optimal management of infected children in the abused population grows, so will clinician ability to use this information to help unravel the often complicated problem of the diagnosis of sexual abuse of children.

\section{REFERENCES}

1. Tilelli JA, Turek D, Jaffe AC. Sexual abuse of children. Clinical findings and implications for management. N Engl J Med 1980;302:319-23.

2. Khan M, Sexton M. Sexual abuse of young children. Clin Pediatr 1983;22:369-72.

3. Grant LJ. Assessment of child sexual abuse: Eighteen month's experience at the Child Protection Center. Am J Obstet Gynecol 1984; 148:617-20.

4. Rimsza ME, Niggemann EH. Medical evaluation of sexually abused children: A review of 311 cases. Pediatrics 1982;69:8-14.

5. Badgley RF, Chair. Sexual offences against children: Report of the Committee on Sexual Offences Against Children and Youths (catalogue number J2-50/1984). Departments of Justice and of National Health and Welfare, Ottawa, 1984.

6. Finkel KC. Sexual abuse of children in Canada. Can Med Assoc J 1984; 130:345-8. 
7. White ST, Loda FA, Ingram DL, Pearson A. Sexually transmitted diseases in sexually abused children. Pediatrics 1983;7:16-21.

8. DeJong AR. Sexually transmitted diseases in sexually abused children. Sex Transm Dis 1986;13:123-6.

9. Peters JJ. Children who are victims of sexual assault and the psychology of offenders. Am J Psychother 1976:30:398-421.

10. Horowity J, Salt P, Gomes-Schwartz B, Sauzier M. Unconfirmed cases of child abuse. In: Tufts New England Medical Center, Division of Child Psychiatry. Sexually Exploited Children: Service and Research Project (1984). (Quoted in Sink F. Studies of true and false allegations: A critical review, 1987).

11. Tanner JM, Whitehouse RH. Clinical longitudinal standards for height, weight, weight velocity, and stages of puberty. Arch Dis Child 1976;51:170-7.

12. Aral SO, Holmes KK. Epidemiology of sexual behaviour and sexually transmitted diseases. In: Holmes KK, Mardh P-A, Sparling PF, Wiesner PJ, eds. Sexually Transmitted Diseases, 2nd edn. New York: McGraw-Hill Book Co, 1989.

13. Ingram DL, White ST, Durfie MF, Pearson AW. Sexual contact in children with gonorrhea. Am J Dis Child 1982;136:994-6.

14. Farrell MK, Billmire E, Shamroy JA, Hammond JG. Prepubertal gonorrhea: A multidisciplinary approach. Pediatrics 1981;67:151-3.

15. Sgroi SM. Pediatric gonorrhea beyond infancy. Pediatr Ann 1979;8:73-87.

16. Alexander WJ, Griffith H, Housch JG, Holmes JR. Infections in sexual contacts and associates of children with gonorrhea. Sex Transm Dis 1984;11:156-8.

17. Bartley DL, Morgan L, Rimsa ME. Gardnerella vaginalis in prepubertal girls. Am J Dis Child 1987;141:1014-7.

18. Hammerschlag MR, Doraiswamy B, Cox P, Cummings M, McCormack WM. Colonization of sexually abused children with genital mycoplasmas. Sex Transm Dis 1987; 14:23-5.

19. Ingram DL, Runyan $\mathrm{DK}$, Collins $\mathrm{AD}$, et al. Vaginal Chlamydia trachomatis infection in children with sexual contact. Pediatr Infect Dis 1984;3:97-9.

20. Ingram DL, White ST, Occhiuti AR, Lyna PR. Childhood vaginal infections: Associations of Chlamydia trachomatis with sexual contact. Pediatr Infect Dis 1986;5:226-9.

21. Schachter J, Grossman M, Sweet RL, Holt J, Jordan C, Bishop E. Prospective study of perinatal transmission of Chlamydia trachomatis. JAMA 1986;255:3374-7.

22. Al-Salihi FL, Curran JP, Wang J-S. Neonatal Trichomonas vaginalis: Report of three cases and review of the literature. Pediatrics 1974;53:196-200.

23. Hammerschlag MR, Alpert S, Rosner I, et al. Microbiology of the vagina in children: Normal and potentially pathogenic organisms. Pediatrics 1978;62:57-62.

24. Foy HM, Kenny GE, Levinsohn EM, Grayston JT. Acquisition of mycoplasmata and T-strains during infancy. J Infect Dis 1970;121:579-87.

25. Davis AJ, Emans SJ. Human papilloma virus infection in the pediatric and adolescent patient. J Pediatr 1989;115:1-9.

26. Rock B, Naghashfar Z, Barnett N, Buscema J, Woodruff JD, Shah K. Genital tract papillomavirus infection in children. Arch Dermatol 1985;122:1129-32.

27. Neinstein LS, Goldenring J, Carpenter S. Nonsexual transmission of sexually transmitted diseases: An infrequent occurrence. Pediatrics 1984;74:67-76.

28. Shore WB, Winkelstein JA. Nonvenereal transmission of gonococcal infections to children. J Pediatr 1971;79:661-3.

29. Wald ER, Woodward CL, Marston G, Gilbert LM. Gonorrheal disease among children in a university hospital. Sex Transm Dis 1980;7:41-3.

30. Frewen TC, Bannatyne RM. Gonococcal vulvovaginitis in prepubertal girls. Clin Pediatr 1979; 18:491-3.

31. Whittington WL, Rice RJ, Biddle JW, Knapp JS. Incorrect identification of Neisseria gonorrhoeae from infants and children. Pediatr Infect Dis J 1988;7:3-10.

32. Rettig PJ, Nelson JD. Genital tract infection with Chlamydia trachomatis in prepubertal children. J Pediatr 1981;99:206-10.

33. Bump RC. Chlamydia trachomatis as a cause of prepubertal vaginitis. Obstet Gynecol 1985;65:384-8.

34. Hammerschlag MR. Chlamydial infections. J Pediatr 1989;114:727-34.

35. Tam MR, Stamm WE, Handsfield HH, et al. Culture-independent diagnosis of Chlamydia trachomatis using monoclonal antibodies. N Engl J Med 1984;310:1146-50.

36. Porder K, Sanchez N, Roblin PM, McHugh M, Hammerschlag MR. Lack of specificity of chlamydiazyme for detection of vaginal chlamydial infection in prepubertal girls. Pediatr Infect Dis J 1989;8:358-60.

37. Hammerschlag MR, Rettig PJ, Shields ME. False positive results with the use of chlamydial antigen detection tests in the evaluation of suspected sexual abuse in children. Pediatr Infect Dis J 1988;7:1 1-14.

38. Saikku P, Puolakkainen M, Lienonen M, Nurminen M, Nissinen A. Cross-reactivity between chlamydiazyme and Acinetobacter strains. N Engl J Med 1986;314:922-3.

39. Krech T, Gerhard-Fsadni D, Hofmann N, Miller SM. Interference of Staphylococcus aureus in the detection of Chlamydia trachomatis by monoclonal antibodies. Lancet 1985;i:1161-2.

40. Rothburn MM, Maillinson H, Mutton KJ. False-positive ELISA for Chlamydia trachomatis recognized by atypical morphology on fluorescent staining. Lancet 1986;ii:982-3.

41. Schachter J. Immunodiagnosis of sexually transmitted disease. Yale J Biol Med 1985;58:443-52.

42. Paradise JE, Campos JM, Friedman HM, Frischmuth G. Vulvovaginitis in premenarcheal girls: Clinical features and diagnostic evaluation. Pediatrics 1982;70:193-8.

43. Bacon JL. Pediatric vulvovaginitis. Adolesc Pediatr Gynecol 1989;2:86-93.

44. Hammerschlag MR, Cummings M, Doraiswamy B, Cox P. McCormack WM. Non-specific vaginitis following sexual abuse in children. Pediatrics 1985;75:1028-31.

45. Ronald AR, Albritton W, Chancroid and Hemophilus ducreyi. In: Holmes KK, Mardh PA, Sparling PF, Wiesner PJ, eds. Sexually Transmitted Diseases, 2nd edn. New York: McGraw-Hill Book Co, 1989.

46. Gellert GA, Durfee MJ. HIV infection and child abuse. N Engl J Med 1989;321:685.

47. Hammerschlag MR, Doraiswamy B, Alexander ER, Cox P Price W, Gleyzer A. Are rectogenital chlamydial infections a marker of sexual abuse in children? Pediatr Infect Dis 1984;3:100-4.

48. Dattel BJ, Landers DV, Coulter K, et al. Isolation of Chlamydia trachomatis and Neisseria gonorrhoeae from the genital tract of sexually abused prepubertal females. Adolesc Pediatr Gynecol 1989;2:217-20.

49. Fuster CD, Neinstein LS. Vaginal Chlamydia trachomatis prevalence in sexually abused prepubertal girls. Pediatrics 1987;79:235-8. 


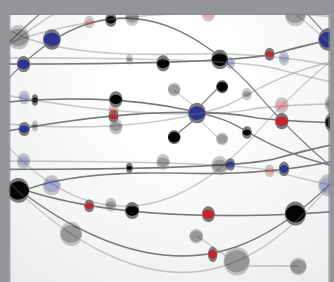

The Scientific World Journal
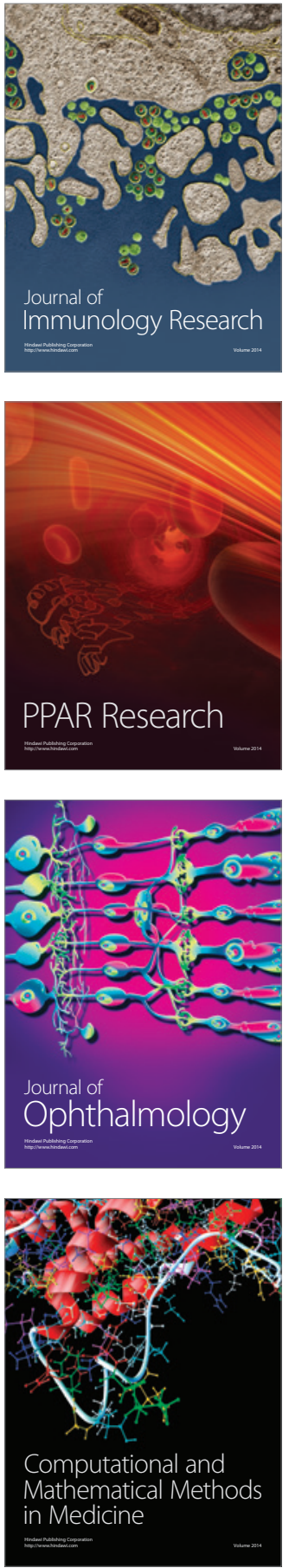

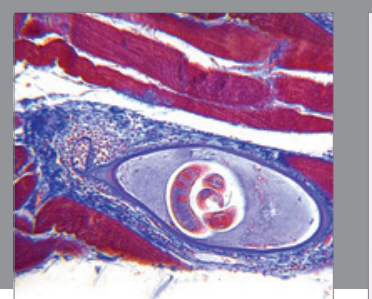

Gastroenterology Research and Practice

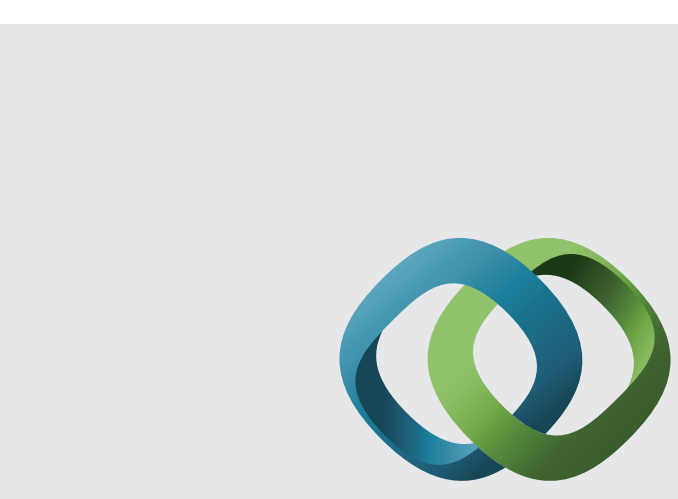

\section{Hindawi}

Submit your manuscripts at

http://www.hindawi.com
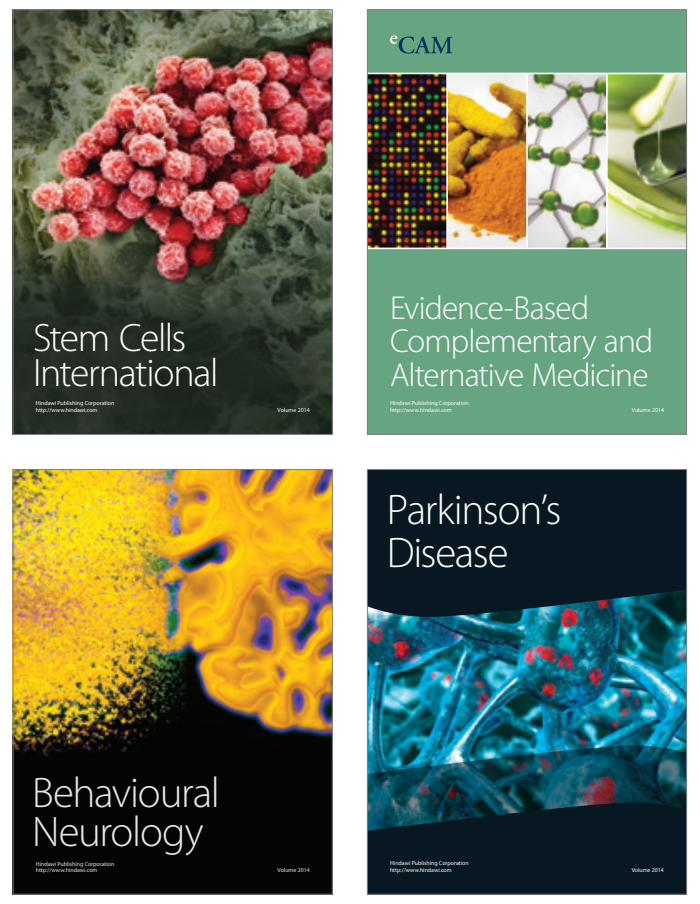
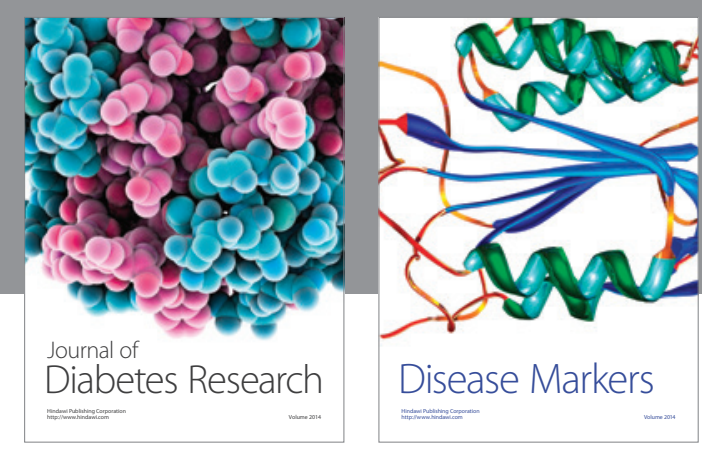

Disease Markers
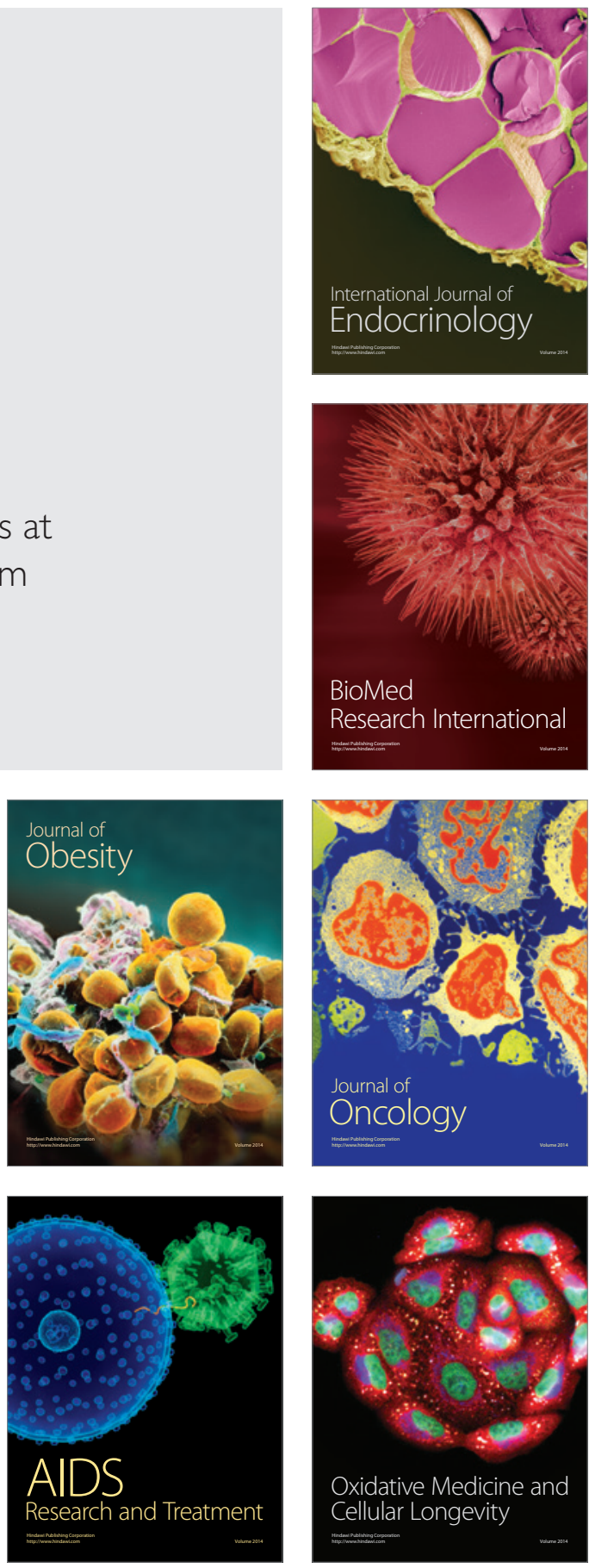